\title{
Study of Representations on Legal Standards in the Structure of Legal Consciousness of Students of Legal Faculties
}

\author{
Larisa Evgenievna Deryagina ${ }^{1, *}$, Valery Borisovich Borovikov ${ }^{2}$, Igor Borisovich \\ Lebedev $^{1}$, Sergey Nikolaevich Tikhomirov ${ }^{3}$, Tatyana Vyacheslavna Maltseva ${ }^{4}$
}

\begin{abstract}
${ }^{1}$ Department of Psychology, Educational and Scientific Complex of Psychology of Service Activities, Federal State Public Educational Establishment of Higher Edication "Moscow University of the Ministry of Internal Affairs of the Russian Federation named after V.Y.Kikot”, Moscow, Russia

${ }^{2}$ Honored worker of higher school of the Russian Federation, Department of criminal law, Federal State Public Educational Establishment of Higher Edication "Moscow University of the Ministry of Internal Affairs of the Russian Federation named after V.Y. Kikot", Moscow, Russia

${ }^{3}$ Department of Pedagogy of the Educational and Scientific Complex of Psychology of Service Activities, Federal State Public Educational Establishment of Higher Edication "Moscow University of the Ministry of Internal Affairs of the Russian Federation named after V.Y. Kikot”, Moscow, Russia

${ }^{4}$ Psychology, pedagogy and organization of work with the staff, the Academy of Ministry of Internal Affairs of Russia, Moscow, Russia

*Corresponding author. Email: lderyagina@mail.ru
\end{abstract}

\begin{abstract}
The article presents research data on the dynamics of the changes in the structure of legal consciousness of law students in the process of higher legal education. The role of legal consciousness in the structure of human existence is shown. The structure, functions and levels of legal consciousness of the individual are analyzed. The specifics of the consciousness of the young people as a socio-demographic group, the interest of the society in a targeted impact on the young generation in order to form stable internal beliefs, which undoubtedly affects the feeling for legal norms among higher education student. The authors note the positive role of legal awareness in forming legal culture among young people. Thirty students of Jurisprudence specialties of the first and fifth courses were examined 15 students in each group. As a method for identifying ideas about legal norms in the structure of law awareness, the method of semantic differential was chosen, which allows us to identify the subjects' ideas about the object under study and to identify the most significant ones. A law awareness structure analysis at the beginning and end of training revealed that all students went through three stages of professionalism: unconscious incompetence, conscious incompetence, conscious competence. By the completion of their studies at the university, students enter the third stage of conscious competence.
\end{abstract}

Keywords: personality, law awareness, training, law students, education

\section{INTRODUCTION}

In the process of education and upbringing under the influence of public opinion, social and subjective factors, a person adopts the legal norms existing in the society, which, having turned into his personal beliefs, become internal motives of behavior $[1,2]$. This means that in the process of influence, legal consciousness, as a sociocultural phenomenon, has a definite effect on forming value orientations of the individual and on the legal culture as the part of the general human culture [3,
4]. Legal consciousness is important for many areas of human existence; it is important for the individual's development, civil society, various social relations; it interacts and complements other forms of social consciousness (economic, moral, political, etc.) [5]. The structure of legal consciousness encompasses 1) legal ideas and beliefs assigned by people in the process of understanding legal information; 2) an effective attitude to law and legal phenomena; 3) behavior motivation in legally significant situations. The affective aspect of justice has relatively stable and less persistent components. Stable components, as a rule, are manifested in traditions, social stereotypes of attitudes to law or legal 
phenomena, labile components - in an emotional attitude to specific situations in the form of the mood, situational emotional response. The motivational component of justice is the attitude towards implementing pro-social or anti-social behavior; supporting or condemning offenses; ignoring or assisting law enforcement officers.

Legal consciousness levels distinguished depend on the scale of the social community: 1) public ones (among the majority of members of society), 2) group ones (of individual social groups), 3) individual ones (of each individual person) [6]. The depth and development of professional legal knowledge determine the types of legal consciousness: 1) everyday (from the experience of everyday life, from the media, from customs, traditions, ethical standards of behavior); 2) professional (from the content of professional legal education and practice); 3) scientific (used by theorists of law, acts in the form of various theories and concepts).

Functions of legal consciousness: 1) cognitive (accumulation of knowledge about legal phenomena); 2) evaluation (development of an emotional attitude to the phenomena of the field of the law); 3) regulatory (organization of human behavior in accordance with legal standards adopted in the society) [7]. Based on this, we single out the educational function of legal awareness, since a high level of legal awareness is a necessary component of the professional training of a lawyer. Of particular relevance at the present stage are the problems of the group level of as a youth socio-demographic group, the public's interest in turgidly influencing the young generation with the aim of forming stable internal beliefs in it, put forward the problems of objective and subjective factors of forming the orientation resulting in law abiding behavior, to the legal consciousness of the youth [8]. Therefore, psychological science faces the task of studying the legal consciousness of both the society as a whole and the youth in particular [9].

To study legal awareness, we made an attempt to study its features in first-year and graduate students studying in legal specialties [10]. During the study, students were asked questions related to crime problems and ways to solve them.

The purpose of the study was to identify the characteristics of ideas about legal norms in the structure of legal consciousness of young people studying the law.

\section{METHODOLOGY}

A comparative analysis of the ideas of legal norms in the structure of legal consciousness among Law students of the first and graduate courses of universities was organized. The object of the study was the legal norms in the structure of legal consciousness. The subject of the study was the peculiarities of the legal norm perception in the legal consciousness structure among students of the "Jurisprudence" specialization.

\section{Research compositional design:}

1. drawing up a questionnaire for the set of the semantic differential objects and descriptors;

2 . conducting a questionnaire survey of the students of the "Jurisprudence" specialization of the first and graduate courses;

3. compilation of and implementing the semantic differential method.

Characteristics of the selection: law students, the 1st and final year. The selection is heterogeneous by sex, the age of the subjects is 17-25 years. The number of respondents is 15 people in each group. Totally 30 people.

As a means of collecting information for compiling a semantic differential, a questionnaire was used based on the literature $\mathrm{n}$ analysis.

As a method for identifying ideas about legal norms in the structure of law awareness, we chose the method of semantic differential, which allows us to reveal the subjects' ideas of the object under study and to identify the most significant ones.

The compiled form of the semantic differential was supplemented by guidelines and filled in by the respondents under the supervision of the experimenter after the oral instructions. The data of the filled-in semantic differential forms were processed using the STATISTICA 6.0 program and multivariate statistics methods were used: hierarchical agglomerative cluster analysis with a dendrogram construction and factor analysis (principal component method).

\section{RESULTS AND DISCUSSION}

In the structure of the legal norm ideas of the 1st year students, three groups of objects can be distinguished (Fig. 1). The first group includes the ideal fighter against crime, the ideal state of law, a just society, I am perfect. The second group includes a typical crime fighter, criminal structures, a state with a high crime rate, a disrespectful attitude to the law and legal norms, and a civilian who is somewhat distanced from the objects of his group. The third group is one object "I". 


\section{Tree Diagram for Variables \\ Single Linkage \\ Euclidean distances}

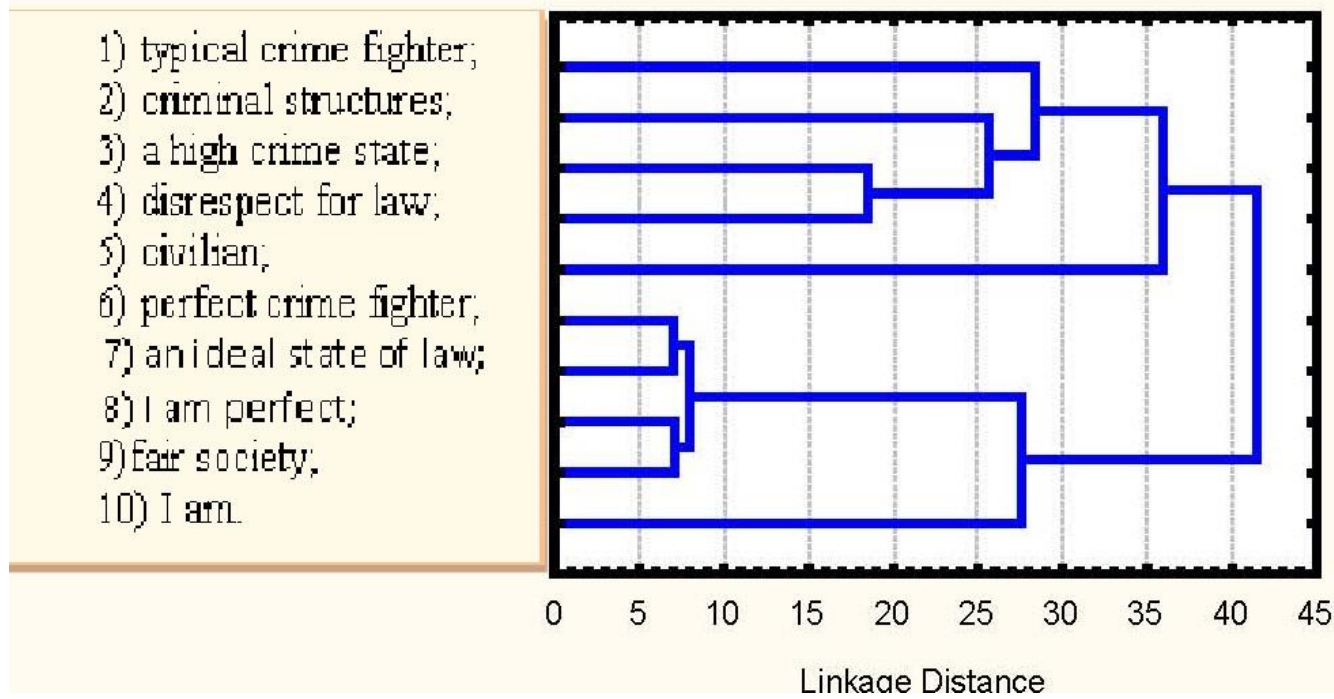

Figure 1 Distribution by social roles related to legal consciousness for 1st year students

The graduate students revealed a different structure of their legal norm ideas. Fig. 2 distinctly shows 4 groups of objects.

The first is a typical crime fighter, I, criminal structures and I am perfect. The second group is a civilian person

Tree Diagram for Variables

Single Linkage

Euclidean distances and disrespectful attitude to the law and legal norms. The third group includes a state with a high crime rate. The fourth group consists of a just society and an ideal legal state.

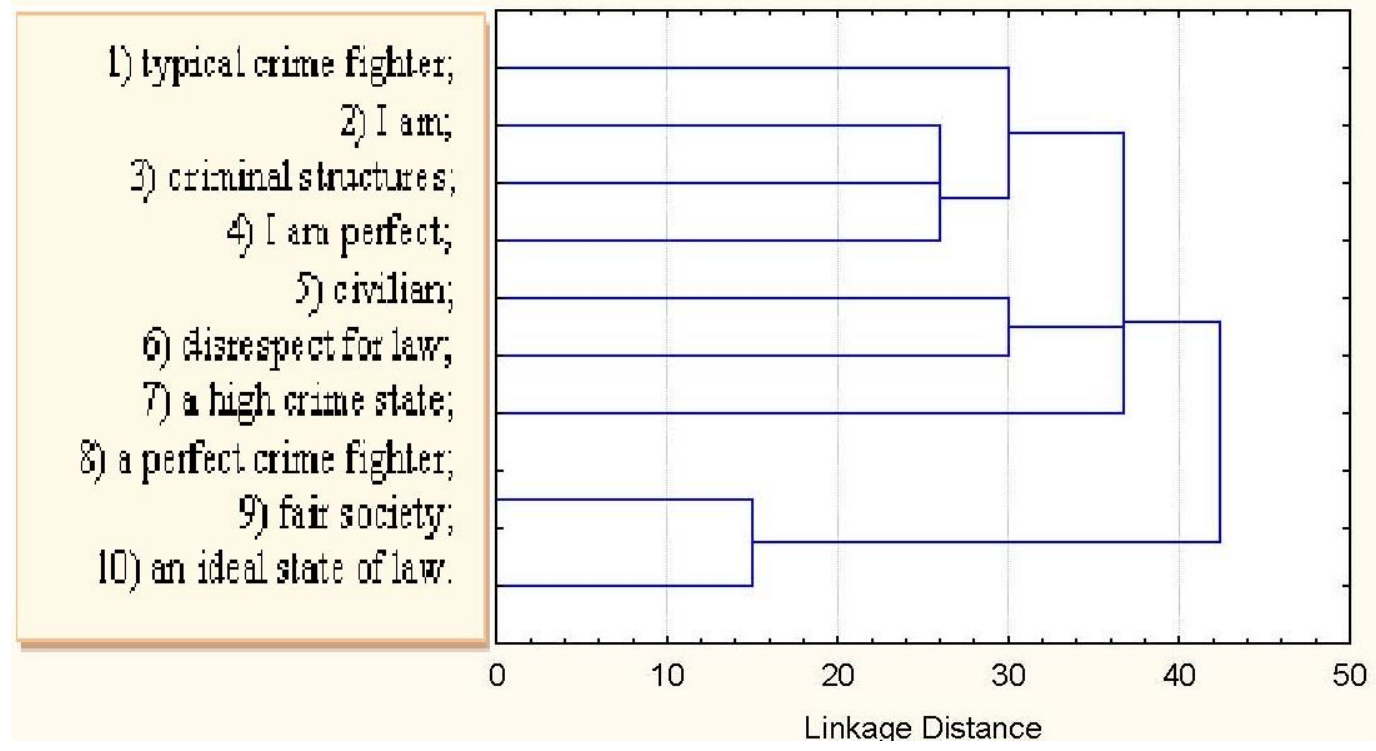

Figure 2 Distribution of social roles related to legal awareness for graduate students 
There is also an ideal crime fighter. The object "I" is located separately and has a very weakly expressed connection with everything ideal.

The students do not consider themselves to be typical crime fighters who are intertwined with criminal structures, nor to disrespect for the law and legal norms. The subjects distinguish themselves and civilians, who, although they are in the second "negative" group, have a very weak relationship with it and, therefore, are mostly more law-abiding than antisocial.

The graduate course demonstrates a completely opposite picture. If the 1 st year students are neutral towards themselves, then the graduate students view themselves and ideal themselves close to a typical crime fighter and criminal structures. Most likely, this is explained by the fact that graduate students are aware that after receiving a diploma they will have to deal with both law enforcement bodies and criminals, so "I" and "I am ideal" are located in this group. It can be assumed that young romantic maximalism is not replaced by the romantic pragmatism of the graduate young people. The stake is no longer made on the desired, but on the real situation in the country. An ordinary citizen is associated with disrespect for the law, in contrast to the perceptions of the first-year students. An

\section{Tree Diagram for Variables Single Linkage Euclidean distances}

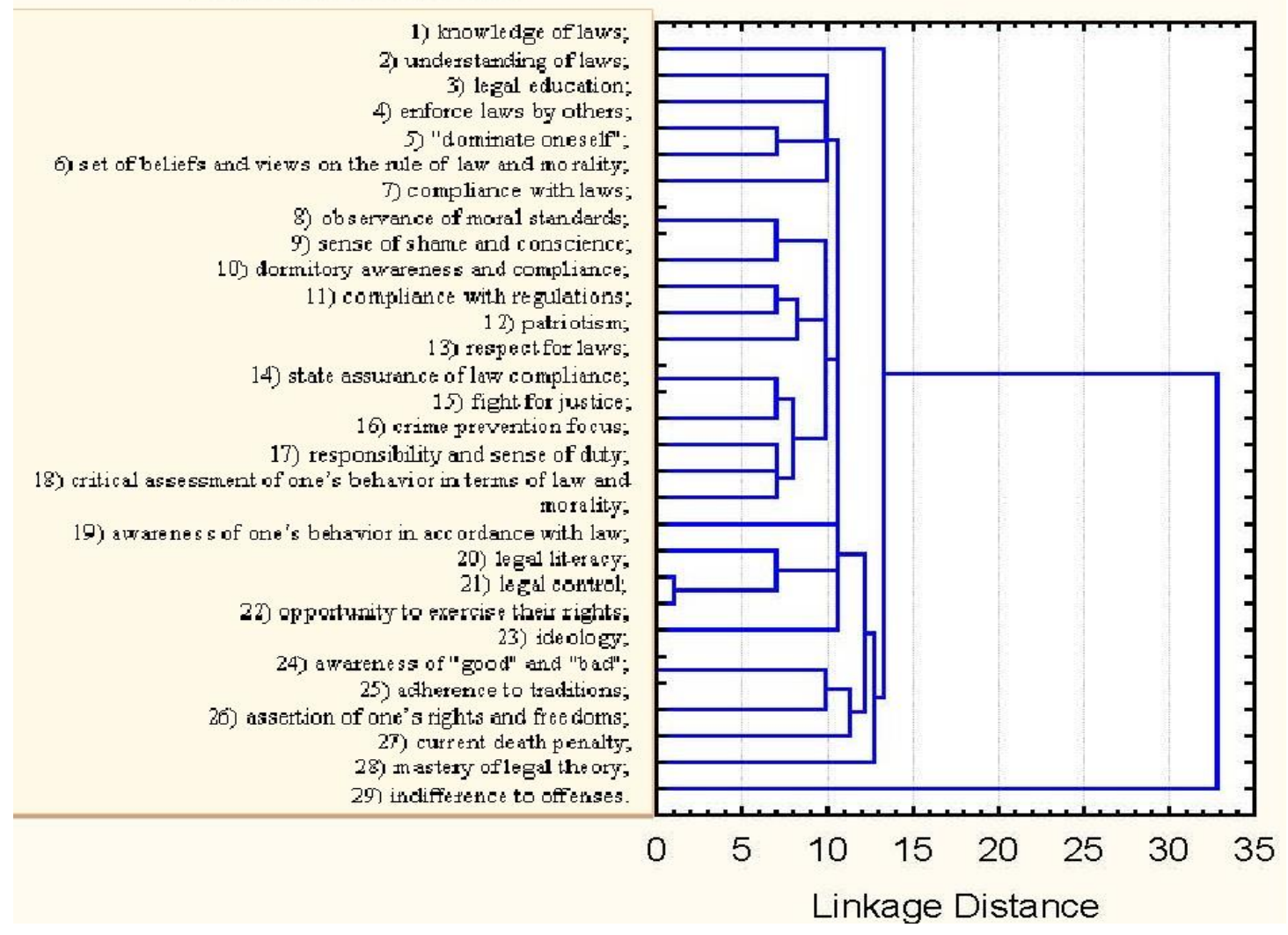

Figure 3 Classification by legal consciousness components for 1 st year students ideal legitimate state, a just society, and an ideal fighter against crime are a single entity, as in the first year, but the graduation course, unlike the first, does not include the ideal itself into this structure. The object "a state with a high crime rate" constitutes a separate group and with a very weak degree of manifestation is associated with a typical crime fighter, with criminal structures, with "I" and "I am ideal". This may indicate that, according to the graduate students, the presence of criminal structures in the state does not guarantee a high level of crime, possibly because of its latency. It is interesting to note that the $1 \mathrm{st}$ year students identify the "state with a high crime rate" object with criminal structures, with disrespectful attitude to the law, and with a typical crime fighter.

According to the results of the cluster analysis on the semantic differential descriptors (Fig. 3) of the both courses, it can be noted that in the 1st year, almost all descriptors, except for indifference to offenses, are approximately close to each other and carry approximately the same power load. The isolation of the "indifference to offenses" descriptor may indicate that the 1st year subjects are not inclined to attribute this quality to themselves, in contrast to other, more positive characteristics. 
At the graduation course (Fig. 4), almost all descriptors are also located together, but apart from the separately located indifference to crimes with the same power load, the descriptor "shame, conscience" is close. The proximity of these two descriptors does not have to mean that they are identical, perhaps, as noted above, the fifthyear students realize that in their professional activities they will have to deal not only with law enforcement agencies, but also with criminal structures, which is part

\section{Tree Diagram for Variables$$
\text { Single Linkage }
$$$$
\text { Euclidean distances }
$$

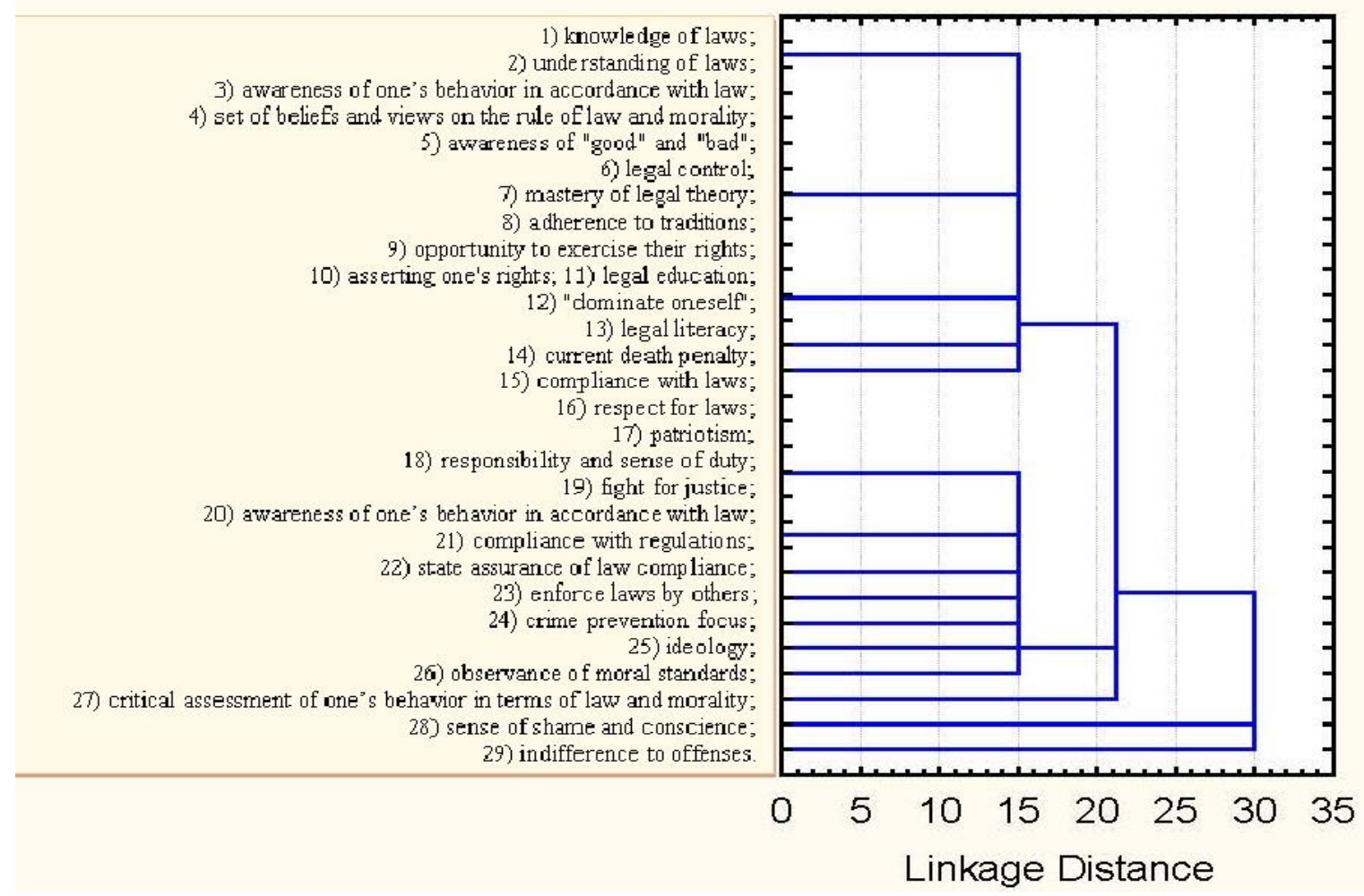

Figure 4 Classification by components of justice for graduate students

Judging by the load, this is the most significant factor for the students. The bipolarity of the "legal literacy is indifference to offenses" factor with the load of 7.02 can tell us that, in the understanding of the respondents, a of the work, which is probably why they separated the feeling of shame from the main descriptors.

According to the results of factor analysis of the semantic differential data of the 1st year students (Table 1), 3 factors were identified. In the first factor, the component "law abidingness, moral standards" is opposed to the component "indifference to offenses" with factor load of 9.63 .

Table 1 Results of the factorial analysis of justice students concepts of first course

\begin{tabular}{|c|c|}
\hline Factor name & Factor load \\
\hline 1. Compliance with laws, moral standards - indifference to offenses & 9,63 \\
\hline 2. Legal literacy - indifference to offenses & 7,02 \\
\hline 3. Compliance with regulations, standards of conduct - patriotism & 3,41 \\
\hline
\end{tabular}


According to the third factor with the load of 3.41, we can conclude that compliance with the requirements and norms of behavior is opposed to patriotism. Perhaps a patriotic person does not have to comply with moral standards and regulations imposed on him by society. In the group of the graduate subjects, 4 significant factors

Table 2 Results of the factorial analysis of representations of justice graduate students

\begin{tabular}{|c|c|}
\hline Factor name & Factor load \\
\hline 1. Respect for laws, the struggle for justice - a sense of shame & 6,37 \\
\hline 2. Legal education, assertion of one's rights - a sense of shame & 2,76 \\
\hline 3. Death penalty - indifference to offenses & 2,76 \\
\hline 4. Legal literacy - self-criticism & \\
\hline
\end{tabular}

Apparently, a citizen who respects the laws, has legal knowledge, who is accustomed to defending his rights has nothing to feel ashamed of. The third bipolar factor is "the death penalty - indifference to offenses" with the power load of 2.76. Obviously, the respondents contrast the death penalty with indifference to offenses. Most likely, it can be assumed that, according to the graduate students, the presence of the death penalty in the Criminal law will not imply indifference to offenses. With the similar factor load of 2.76, the fourth factor "Legal literacy - selfcriticism" was determined.

It is interesting to note that in the descriptor dendrogram for the graduation courses, it is clearly seen that the death penalty is identified with legal literacy, legal education, the development of law theory and the knowledge of rights and freedoms. Consequently, it can be assumed that the death penalty in the understanding of the subjects is an acceptable sanction for serious crimes in an ideal legitimate state.

The fourth factor, "legal literacy - self-criticism" with the load of 2.76 can be interpreted as saying that a person striving for legal literacy by acquiring a higher legal education goes through three stages of professionalism: unconscious incompetence, conscious incompetence, and conscious competence. By the end of their studies at the university, students enter the third stage of conscious competence, where the level of self-criticism is significantly reduced. This, perhaps, explains the contrast between legal literacy and self-criticism.

\section{CONCLUSION}

And so, the study of the legal consciousness of students studying in legal specialties shows that it depends on various factors: the quality of training, including its connection with practical legal activity, the acquisition of life, social experience, moral values that prevail in society, the right psychological attitudes that focus on willingness to perform complex and time-consuming tasks were identified for them (Table 2). The first factor is "respect for laws, the struggle for justice - a sense of shame" with the load of 8.37 . The second factor is "legal education, defending one's rights - a sense of shame" with the load of 6.83 . that require constant work with legislation and the practice of its application.

Thus, based on the results obtained, we can come to the conclusion on the dynamics of beliefs in the structure of legal consciousness in accordance with the age and stages of professionalization for law students. These data are important for adequately developing the university educational activities and recording and preventing the potential risks of legal awareness formation.

\section{REFERENCES}

[1] M.E. Vdovin, I.A. Ilyin, "On Legal

Consciousness" and the Building of a "Civil Society" in Russia: Some Studies, Legal Science: History and Present 12 (2016) 193-195.

[2] M.A. Gusarova, The problem of legal consciousness as a sociocultural phenomenon, Historical, philosophical, political and legal sciences, cultural studies and art history. Questions of theory and practice 9(83) (2017) 73-75.

[3] E.V. Arakelova, E.V. Sergeev, Problems of the formation of youth legal awareness in modern sociocultural conditions of Russian reality, Bulletin of the Adygea State University. Series 1: Regional Studies: Philosophy, History, Sociology, Law, Political Science, Cultural Studies 3(224) (2018) 77-80.

[4] M.A. Gusarova, Legal ideology and legal psychology in modern Russian society: analysis of correlation relationships, Historical, philosophical, political and legal sciences, cultural studies and art history. Questions of theory and practice 2(76) (2017) 79-82. 
[5] A.V. Vakhterov, The upbringing of spiritual and moral principles in legal consciousness as the basis for the effectiveness of public administration,

Psychopedagogy in law enforcement agencies 1(32)

(2008) 22-24.

[6] O.V. Peresadina, The place and role of legal principles in professional legal consciousness, Person, law, state 3 (2018) 112-122.

[7] A.I. Abramov, The functions of legal awareness and their role in the implementation of the function of law, News of higher educational institutions.

Jurisprudence 5(268) (2006) 23-35.

[8] LC. Alvaro-Gonzalez, Neuroethics (I): moral pathways in normal brain, Rev Neurol 1,58(5) (2014) 225-33.

[9] A. Berestova, N. Gayfullina, S. Tikhomirov, Leadership and functional competence development in teachers: world experience, International Journal of Instruction 13,1 (2020) 607.

[10] R. Muslumov, A. Pecherkina, Conditions of the Effective Formation of Legal Consciousness of Students By Means of Psychological Training, in: The Fifth International Luria Memorial Congress "Lurian Approach in International Psychological Science", KnE Life Sciences, 2018, pp. 625-636. 